\title{
44
}

\section{Evolution (Multiple Choice)}

Wer sind wir? Woher kommen wir? Seit Menschengedenken stellen wir uns Fragen wie diese. Wertvolle Einblicke in unsere Abstammungsgeschichte gewährt die Evolutionsbiologie. Wähle die jeweils richtige Antwort aus und bilde das Lösungswort aus den erhaltenen Buchstaben.

\section{Andere Bezeichnung für die Menschenartigen}

(E) Homini (C) Homonaden (A) Hominiden

2. Begründer der Evolutionstheorie

(T) Darwin (V) Lamarck (H) Linné

3. Gesamtheit der genetischen Variationen einer Population

(O) Genom (A) Genpool (E) Gentopf

4. Der "Urvogel"

(R) Pteranodon (V) Archaeopteryx (P) Erectus

5. Merkmal mehrerer Arten, das auf einen (ihnen gemeinsamen) Ahnen zurückgeht

(I) Homologie (E) Analogie (U) Symmetrie

6. Nicht ausgestorben; heute lebend

(M) vivipar (R) rezessiv (S) rezent

7. Durch Umweltbedingungen erzwungene Veränderung und Anpassung

(T) Gendrift (M) Selektionsdruck (U) Radiation

8. Uneigennütziges Verhalten zum Wohle anderer

(E) Symbiose (U) Altruismus (O) Koevolution

9. Informationseinheit der kulturellen Evolution

(S) Mem (N) Erfahrung (L) Gen

Lösung: 